\title{
Interstitial lung disease in clinically amyopathic dermatomyositis with and without anti-MDA-5 antibody: to lump or split?
}

Satoshi Ikeda ${ }^{1 *} \mathbb{D}$, Machiko Arita', Mitsunori Morita', Satoshi Ikeo', Akihiro Ito ${ }^{1}$, Fumiaki Tokioka', Maki Noyama', Kenta Misaki ${ }^{2}$, Kenji Notohara ${ }^{3}$ and Tadashi Ishida ${ }^{1}$

\begin{abstract}
Background: Interstitial lung disease (ILD) associated with clinically amyopathic dermatomyositis (CADM-ILD) is often refractory and rapidly progressive. Although the anti-melanoma differentiation-associated gene 5 (anti-MDA-5) antibody is associated with rapidly progressive ILD (RP-ILD), differences in clinical features and prognosis of anti-MDA-5 antibody-positive and -negative CADM-ILD remain unclear.

Methods: To clarify the differences in the clinical features and prognosis between anti-MDA-5 antibody-positive and -negative cases, we retrospectively reviewed the medical records of patients diagnosed with CADM-ILD with and without anti-MDA-5 antibody at Kurashiki Central Hospital from January 2005 to September 2014.

Results: Anti-MDA-5 antibody was found in 10 of 16 patients (63\%). The levels of Krebs von den Lungen-6 (KL-6) and surfactant protein D (SP-D) at the first visit were significantly lower in positive patients than in negative patients, whereas the levels of aspartate aminotransferase (AST), $\gamma$-glutamyl transpeptidase $(\gamma-G T P)$, and the $C D 4^{+} / C D 8^{+}$ratio in the bronchoalveolar lavage (BAL) fluid were significantly higher in positive patients than negative patients. Subpleural ground-glass opacity (GGO) or irregular linear opacity was predominant in positive patients. Peribronchovascular consolidation was predominant in negative patients. Positive patients had significantly lower survival rates than negative patients, with all six fatal cases occurring in positive patients who died of refractory ILD within 92 days from the first visit despite intensive treatment.

Conclusions: There are clear differences in the clinical features and prognosis of anti-MDA-5 antibody-positive and -negative CADM-ILD. Low serum KL-6 and SP-D levels, high serum AST and $\gamma$-GTP levels, high CD4 ${ }^{+} / \mathrm{CD}^{+}$ratio in BAL fluid, and predominance of subpleural GGO or irregular linear opacity in HRCT may help to discriminate anti-MDA-5 antibody-positive CADM-ILD with poor prognosis.
\end{abstract}

Keywords: Amyopathic dermatomyositis, Interstitial lung diseases, MDA-5 protein, human, Melanoma differentiation associated protein-5, human

\footnotetext{
* Correspondence: isatoshi0112@gmail.com

${ }^{1}$ Department of Respiratory Medicine, Kurashiki Central Hospital, Miwa 1-1-1, Kurashiki-city, Okayama 710-8602, Japan

Full list of author information is available at the end of the article
} 


\section{Background}

Interstitial lung disease (ILD) is the most common internal organ manifestation that affects the prognosis of clinically amyopathic dermatomyositis (CADM), as well as polymyositis (PM) and dermatomyositis (DM). ILD associated with CADM (CADM-ILD) is often refractory and rapidly progressive [1-3], resulting in respiratory failure with a 6-month survival rate of 40.8-54.5\% [3-5]. Although no standard treatment regimen for CADM-ILD has been established, intensive treatment with the threedrug combination of corticosteroid, cyclosporine, and cyclophosphamide is recommended in the early phase even if respiratory symptoms are absent or mild [6, 7].

Among patients with CADM, anti-melanoma differentiation-associated gene 5 (MDA-5) antibodies are strongly associated with the development of rapidly progressive ILD (RP-ILD) [8-10]. As MDA-5 plays the critical role in the innate immune defense against viruses, one hypothesis is that the production of anti-MDA-5 antibodies is a secondary phenomenon during virus infection that is associated with the onset of CADM and RP-ILD. However, to our knowledge, no previous study has revealed whether the presence or absence of the antiMDA-5 antibody affects the clinical manifestation of CADM-ILD.

In the present study, we retrospectively reviewed consecutive cases of CADM-ILD to clarify the differences in the clinical features and prognosis between anti-MDA-5 antibody-positive and -negative cases, and to determine whether we should separate CADM-ILD by the presence or absence of anti-MDA-5 antibody.

\section{Methods}

\section{Patients and settings}

This retrospective study was performed at Kurashiki central hospital in Kurashiki city, Okayama, Japan. The patients diagnosed with CADM-ILD at our hospital from January 2005 to September 2014 who had cryopreserved blood serum before starting treatment were enrolled in this study. Diagnoses of CADM were made by at least two pulmonologists and one rheumatologist based on the criteria of Sontheimer [11]. In addition, patients who exhibited a rash typical of DM without muscle weakness for less than 6 months and experienced fatal complications such as acute/subacute ILD were also diagnosed with CADM according to Gerami et al.'s criteria [12]. No exclusion criteria were specified. The Ethics Committee of Kurashiki Central Hospital approved the study protocol. The Ethics Committee approved the waiver of each patient's consent because it was a retrospective study and high anonymity was secured.

\section{Identification of myositis-specific antibodies}

Measurement of myositis-specific antibodies was carried out by using cryopreserved blood serum before starting treatment. Serum anti-MDA-5 antibody was measured by immunoprecipitation using ${ }^{35} \mathrm{~S}$-labeled $\mathrm{HeLa}$ cell extract (Perkin Elmer, Waltham, MA, USA), which was confirmed by enzyme-linked immunosorbent assay (SRL, Tokyo, Japan). Other myositis-specific antibodies, including antiaminoacyl transfer RNA synthetase (anti-ARS) antibodies, were measured using the Myositis Profile Euroline antibody test system (EUROIMMUN, Lubeck, Germany), which was confirmed by RNA immunoprecipitation (Bio-Rad Laboratories, Hercules, CA, USA).

\section{Clinical and laboratory findings}

Clinical data and laboratory data used in the present study were retrieved from patient medical records and included gender, age, smoking history, length of time from onset of symptoms to first visit, department of the first visit, symptoms and physical examination, laboratory data, and results of bronchoalveolar lavage (BAL) and pulmonary function tests. BAL was routinely performed under local anesthesia before starting treatment. The bronchoscope was wedged into the segmental bronchi. Only samples with recovery $>25 \%$ were used. With regards to pulmonary function test, forced vital capacity and diffusing capacity for carbon monoxide were measured using same machine and same method in all patients. Values were expressed as a percentage of the predicted value.

\section{Radiological findings}

All patients underwent high-resolution computed tomography (HRCT) at the time of diagnosis, and HRCT findings were reviewed and interpreted by board-certified pulmonologists and radiologists. Images were assessed for the dominant craniocaudal/ axial distribution and the dominant shadow [consolidation, ground-glass opacity (GGO), reticulation, or irregular linear opacity]. The presence of traction bronchiectasis, cyst, subpleural curve linear shadow, thickening of the perilymphatic interstitium, emphysema, and loss in lung volume were also assessed. HRCT protocol and machine was the same for all included patients at peak tube voltage of $120 \mathrm{kVp}$ and approximately $\leq 240 \mathrm{mAs}$ using an automatic exposure control system (Toshiba Medical Systems, Tochigi, Japan).

\section{Statistical analysis}

Categorical data are presented as numbers (percentages), while continuous data are presented as medians (interquartile ranges). Fisher's exact test was used to compare categorical data, and the Mann-Whitney $U$ test was used to compare continuous data. Cumulative survival probabilities were estimated using the Kaplan-Meier method. The log-rank test was used to compare survival 
among patient groups. A $p$ value of $<0.05$ was considered statistically significant.

\section{Results}

\section{Characteristics}

From January 2005 to September 2014, we encountered 18 cases of newly diagnosed ILD associated with CADM. Anti-MDA-5 antibody was measured in 16 cases who had cryopreserved blood serum before starting treatment. Anti-MDA-5 antibody was present in 10 patients (positive group) and absent in 6 patients (negative group). Patients' characteristics are summarized in Table 1. The median length of time from onset to first visit was shorter in the positive group (15.5 vs. 51.0 days, respectively), although the difference did not reach statistical significance $(p=0.157)$. No significant differences were observed in gender, age, smoking history, or symptoms and signs at the time of diagnosis between the two groups.

\section{Laboratory data}

Laboratory data are summarized in Table 2. Aspartate aminotransferase (AST) and $\gamma$-glutamyl transpeptidase $(\gamma$-GTP) levels were significantly higher $(p=0.0225$ and 0.00225 , respectively) in the positive group when compared to the negative group, whereas serum levels of

Table 1 Summary of clinical characteristics

\begin{tabular}{|c|c|c|c|}
\hline & $\begin{array}{l}\text { MDA-5 positive } \\
(n=10)\end{array}$ & $\begin{array}{l}\text { MDA-5 negative } \\
(n=6)\end{array}$ & $p$ value \\
\hline Gender (male/female) & $6 / 4$ & $2 / 4$ & 0.608 \\
\hline Age & $63.0(58.0-64.8)$ & $71.5(64.8-73.8)$ & 0.0913 \\
\hline Smoking history & $5(50 \%)$ & $2(33 \%)$ & 0.633 \\
\hline Days from onset to first visit & $15.5(11.0-29.8)$ & $51.0(39.5-77.5)$ & 0.157 \\
\hline \multicolumn{4}{|l|}{ Department of the first visit } \\
\hline Respiratory medicine & $6(60 \%)$ & $1(17 \%)$ & - \\
\hline Rheumatology & $2(20 \%)$ & $5(83 \%)$ & - \\
\hline Dermatology & $2(20 \%)$ & 0 & - \\
\hline \multicolumn{4}{|c|}{ Symptoms and signs at the time of diagnosis } \\
\hline Gottron's sign/papule & 7 (70 \%) & $5(83 \%)$ & 1.00 \\
\hline Heliotrope eruption & 7 (70 \%) & $1(17 \%)$ & 0.119 \\
\hline V/shawl neck sign & $5(50 \%)$ & $2(33 \%)$ & 0.633 \\
\hline Mechanic's hands & $2(20 \%)$ & $2(33 \%)$ & 0.604 \\
\hline Palmar erythema & $2(20 \%)$ & $1(17 \%)$ & 1.00 \\
\hline Myalgia & $3(30 \%)$ & 0 & 0.250 \\
\hline Dry cough & $5(50 \%)$ & $4(67 \%)$ & 0.633 \\
\hline Dyspnea on exertion & $5(50 \%)$ & $5(83 \%)$ & 0.307 \\
\hline Fever & 9 (90 \%) & $3(50 \%)$ & 0.118 \\
\hline
\end{tabular}

Categorical data are presented as numbers (percentages) and were analyzed using Fisher's exact test. Continuous data are presented as medians (interquartile ranges) and were analyzed using the Mann-Whitney $U$ test. A $p$ value of $<0.05$ was considered statistically significant

Abbreviation: MDA-5, anti-melanoma differentiation-associated gene 5
Krebs von den Lungen-6 (KL-6) and surfactant protein D (SP-D) at the first visit were significantly lower $(p=0.0160$ and 0.00402 , respectively) in the positive group than in the negative group. In the positive group, serum KL-6 gradually increased, whereas serum SP-D remained consistently low 1-4 weeks after treatment initiation (Fig. 1). In the negative group, one patient each was positive for anti-Jo1 antibody, anti-PL-12 antibody, anti-OJ antibody, and anti-PM/Scl-100 antibody. Regarding BAL fluid analysis, the $\mathrm{CD}^{+} / \mathrm{CD}^{+}$ratio was significantly higher in the positive group than in the negative group $(p=0.0167)$.

\section{HRCT findings}

HRCT findings are shown in Table 3 and Fig. 2. In both groups, there was a predominance of shadows in the lower lobe. Subpleural distribution was predominant in the positive group, whereas peribronchovascular distribution was predominant in the negative group. In the positive group, GGO (50 \%) was the most commonly observed shadow followed by irregular linear opacity (30 \%). Conversely, in the negative group, the most common shadow was consolidation with a significantly higher incidence than in the positive group $(p=0.00762)$. While HRCT findings in the positive and negative group often appeared to be mild, most were associated with loss of lung volume (90 and $83 \%$, respectively) or traction bronchiectasis (50 and $67 \%$, respectively).

\section{Treatments and outcomes}

Three-drug combination therapy with corticosteroid, cyclosporine, and cyclophosphamide was the most common initial treatment in both groups (78 and $83 \%$, respectively). The median follow-up period over both groups was 689 days (the data cutoff date was November 9, 2014). In the present study, six deaths were observed during the follow-up period; all six cases were positive for anti-MDA- 5 antibody and died from refractory ILD within 92 days from the first visit (median, 30.0 days). Five of these six cases received intensive initial treatment with corticosteroid, cyclosporine, and cyclophosphamide. The one remaining case was refractory to the initial treatment with corticosteroid monotherapy, and thus subsequently received cyclosporine and cyclophosphamide.

A comparison of survival curves is shown in Fig. 3. The anti-MDA-5 antibody-positive group had significantly lower survival rates than the negative group $(p=0.0252)$.

\section{Comparison between survivors and non-survivors with anti-MDA-5 antibody}

A comparison between the survivors and non-survivors in the positive group is shown in Table 4. The length of time from onset to the first visit was shorter among the non-survivors than the survivors, although this difference did not reach statistical significance $(p=0.0666)$. 
Table 2 Summary of the results of laboratory testing, bronchoalveolar lavage, and pulmonary function test

\begin{tabular}{|c|c|c|c|}
\hline & $\begin{array}{l}\text { MDA-5 positive } \\
(n=10)\end{array}$ & $\begin{array}{l}\text { MDA-5 negative } \\
(n=6)\end{array}$ & $p$ value \\
\hline $\mathrm{PaO}_{2} / \mathrm{FiO}_{2}$ ratio & $296(274-359)$ & $343(332-357)$ & 0.689 \\
\hline \multicolumn{4}{|l|}{ Laboratory data } \\
\hline White blood cell count $(/ \mu \mathrm{L})$ & $5600(4825-6300)$ & $8150(5775-10150)$ & 0.573 \\
\hline Aspartate aminotransferase (IU/L) & $55.5(40.5-92.3)$ & $28.5(23.5-33.5)$ & 0.0225 \\
\hline Alanine aminotransferase (IU/L) & $27.0(17.0-105)$ & $17.0(16.3-19.3)$ & 0.252 \\
\hline Y-glutamyl transpeptidase (IU/L) & $40.5(23.0-60.5)$ & $15.5(14.0-22.3)$ & 0.00225 \\
\hline Creatine phosphokinase (IU/L) & $184(90.3-467)$ & $108(85.8-268)$ & 0.635 \\
\hline Aldolase (U/L) & $6.15(3.58-8.45)$ & $7.50(4.45-8.45)$ & 0.713 \\
\hline C-reactive protein (mg/dL) & $1.28(0.90-2.94)$ & $0.62(0.36-3.53)$ & 0.428 \\
\hline Lactate dehydrogenase (IU/L) & $368(302-390)$ & $297(259-331)$ & 0.0925 \\
\hline Krebs von den Lungen- $6(\mathrm{U} / \mathrm{mL})$ & $600(471-1072)$ & $1700(1027-3511)$ & 0.0160 \\
\hline Surfactant protein D (ng/dL) & $32.5(22.8-47.6)$ & $181(98.1-378)$ & 0.00402 \\
\hline Anti-ARS antibody & 0 & $3(50 \%)$ & \\
\hline Anti Jo-1 & 0 & $1(17 \%)$ & \\
\hline Anti PL-12 & 0 & $1(17 \%)$ & \\
\hline Anti $0 \mathrm{~J}$ & 0 & $1(17 \%)$ & \\
\hline Anti-PM/Scl-100 antibody & 0 & $1(17 \%)$ & \\
\hline \multicolumn{4}{|l|}{ Bronchoalveolar lavage } \\
\hline Total cell count & $300(250-400)$ & $500(450-700)$ & 0.131 \\
\hline Neutrophil (\%) & $3.00(2.50-6.50)$ & $11.0(8.50-51.5)$ & 0.0855 \\
\hline Eosinophil (\%) & $1.00(0.00-1.00)$ & $4.00(2.00-5.50)$ & 0.284 \\
\hline Lymphocyte (\%) & $30.0(24.5-37.0)$ & $41.0(22.0-42.0)$ & 0.819 \\
\hline Macrophage (\%) & $60.0(59.5-70.5)$ & $41.0(23.0-44.0)$ & 0.0396 \\
\hline $\mathrm{CD} 4+/ \mathrm{CD} 8+$ ratio & $1.68(1.13-3.62)$ & $0.420(0.340-0.490)$ & 0.0167 \\
\hline \multicolumn{4}{|l|}{ Lung function test } \\
\hline$\%$ Forced vital capacity & $79.8(67.4-90.4)$ & $72.9(53.4-93.6)$ & 1.00 \\
\hline \% Diffusing capacity for carbon monoxide & $56.6(50.2-63.7)$ & $56.9(54.7-63.0)$ & 0.730 \\
\hline
\end{tabular}

The length of time from onset to treatment initiation was significantly shorter in non-survivors than in survivors $(p=0.0381)$. As for the HRCT findings, the incidence of GGO was significantly higher among non-survivors than survivors $(p=0.0480)$. No significant differences were observed in terms of gender, age, smoking history, $\mathrm{PaO}_{2} / \mathrm{FiO}_{2}$ ratio, or BAL fluid analysis results between the two groups.

\section{Discussion}

Previous studies, mainly from Asia, have demonstrated that CADM-ILD often runs an aggressive course [3-5]. On the contrary, Cottin et al. reported good treatment response and favorable prognosis of CADM-ILD in France [13]. These results suggest that CADM-ILD includes a heterogeneous disease population. The present study demonstrated the four following important clinical observations. First, serum KL-6 and SP-D at the first visit were significantly lower in the positive group than in the negative group. Second, serum AST, $\gamma$ - GTP, and $\mathrm{CD}^{+} / \mathrm{CD}^{+}$ratio in the BAL fluid were significantly higher in the positive group than in the negative group. Third, radiological findings were quite different between the two groups. Fourth, anti-MDA-5 antibody-positive cases had significantly lower survival rates than antiMDA-5 antibody-negative cases. These clinical differences imply that anti-MDA-5 antibody-positive and -negative CADM-ILD should be regarded as separate entities.

The biomarkers ILD, KL-6, and SP-D are reportedly useful for assessing the prognosis of ILD in PM and DM [14-16]. However, the usefulness of KL-6 and SP-D in CADM-ILD has not been fully investigated in previous research. In the present study, serum levels of KL-6 at 


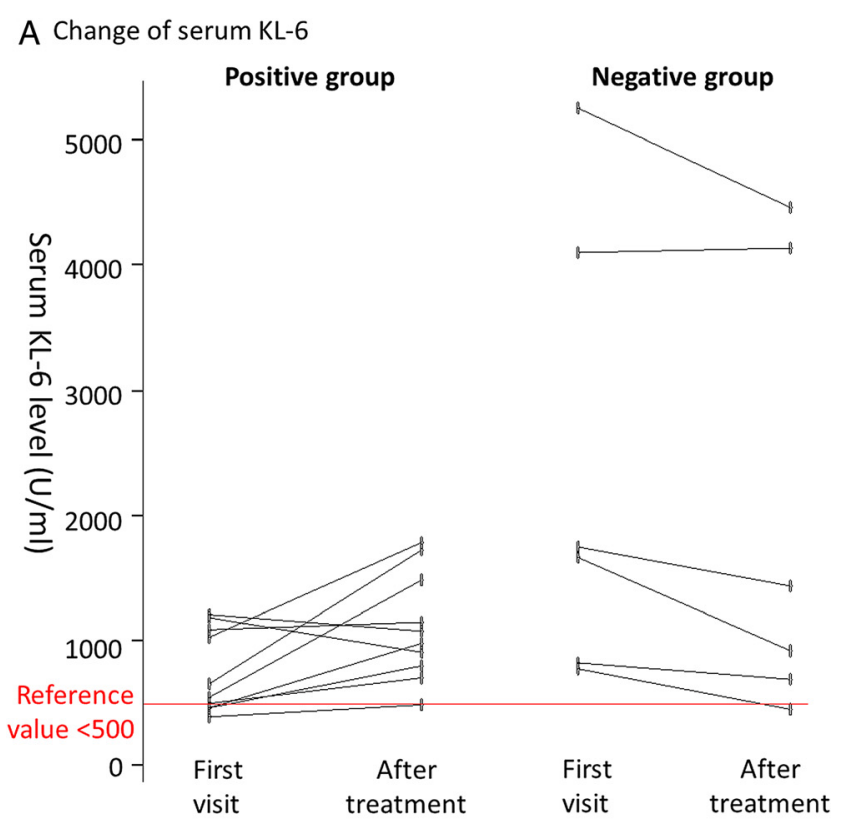

B Change of serum SP-D

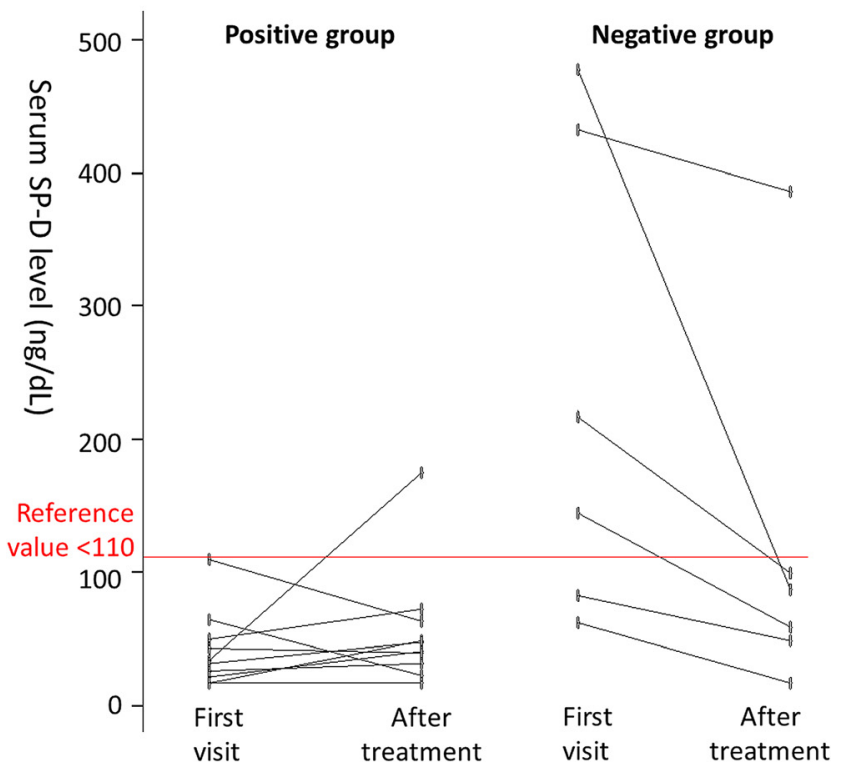

Fig. 1 Chronological changes in serum KL-6 and SP-D. a Serum KL-6 levels at first visit and after 1-4 weeks' treatment initiation in each patient of the anti-MDA-5 antibody positive (left) and negative groups (right). b Serum SP-D levels at first visit and after 1-4 weeks' treatment initiation in each patient of the anti-MDA-5 antibody positive (left) and negative groups (right). Abbreviations: KL-6, Krebs von den Lungen-6; SP-D, surfactant protein D; MDA-5, anti-melanoma differentiation-associated gene 5

the first visit were lower in the positive group than in the negative group but gradually increased in most of the cases during the observation period. Although the cause is not clear, the two following reports may provide clues for resolving this problem. First, Otsuka et al. reported that in the early stage of acute exacerbation of idiopathic pulmonary fibrosis, the elevation in serum KL-6 mostly occurred after the manifestation of symptoms and deterioration of HRCT findings and the other biomarkers of ILD [17]. Second, Sakamoto et al. reported that the serum levels of KL-6 are significantly correlated with the extent of traction bronchiectasis observed in HRCT, which is an indicator of the pathologic grade of fibrosis [18]. As anti-MDA-5 antibodypositive cases tend to progress more rapidly compared with anti-MDA-5 antibody-negative cases, serum KL-6 
Table 3 Comparison of HRCT findings between patients with and without anti-CADM-antibody

\begin{tabular}{|c|c|c|c|}
\hline & $\begin{array}{l}\text { MDA-5 positive } \\
(n=10)\end{array}$ & $\begin{array}{l}\text { MDA-5 negative } \\
(n=6)\end{array}$ & $p$ value \\
\hline \multicolumn{4}{|l|}{ Distribution } \\
\hline Upper lobe dominant & $1(10 \%)$ & 0 & 1.00 \\
\hline Lower lobe dominant & $9(90 \%)$ & $6(100 \%)$ & 1.00 \\
\hline Peribronchovascular & $2(20 \%)$ & $4(67 \%)$ & 0.118 \\
\hline Subpleural & $8(80 \%)$ & $2(33 \%)$ & 0.118 \\
\hline \multicolumn{4}{|l|}{ Main findings } \\
\hline Consolidation & $1(10 \%)$ & $5(83 \%)$ & 0.00762 \\
\hline Ground glass opacity & $5(50 \%)$ & 0 & 0.0934 \\
\hline Reticulation & $1(10 \%)$ & 0 & 1.00 \\
\hline Irregular linear opacity & $3(30 \%)$ & $1(17 \%)$ & 1.00 \\
\hline \multicolumn{4}{|l|}{ Additional findings } \\
\hline Traction bronchiectasis & $5(50 \%)$ & $4(67 \%)$ & 0.633 \\
\hline Cyst & 0 & $1(17 \%)$ & 0.375 \\
\hline Subpleural curve linear shadow & $4(40 \%)$ & $3(50 \%)$ & 1.00 \\
\hline Thickening of interlobular septa & $2(20 \%)$ & $2(33 \%)$ & 0.604 \\
\hline Emphysema & $1(10 \%)$ & $1(17 \%)$ & 1.00 \\
\hline Volume loss & $9(90 \%)$ & $5(83 \%)$ & 1.00 \\
\hline
\end{tabular}

Categorical data are presented as numbers (percentages) and were analyzed using Fisher's exact test

Abbreviations: CADM clinically amyopathic dermatomyositis, HRCT high-resolution computed tomography, MDA-5, anti-melanoma differentiation-associated gene 5

levels may not yet have increased in anti-MDA-5 antibodypositive cases at the first medical examination. However, the higher values of KL- 6 in the negative group might be somewhat affected by 2 subjects who have especially high KL-6 at first visit, thus we must be careful in interpreting the results. On the other hand, serum SP-D levels in the positive group were significantly lower than in the negative group and remained consistently low during the course of treatment. In the negative group, serum SP-D levels decreased after anti-inflammatory treatment in most of the cases. Several studies have reported that serum SP-D concentrations are correlated with the extent of alveolitis (most commonly reflected by increased cellularity in the alveolar interstitium), but not with the progression of fibrosis [19]. Thus, low serum SP-D levels in the positive group may reflect poor cellularity and progressive fibrotic change, whereas high serum SP-D levels in the negative group may reflect relatively abundant cellularity.

As a background to the differences in the KL- 6 and SP-D levels, we believe that immune reactions may differ in the lung between the two groups. The following two results support this supposition. 1) Serum levels of AST and $\gamma$-GTP were significantly higher in the positive group than in the negative group. Elevation of serum hepatobiliary enzymes was reported to be correlated with ILD in anti-MDA-5 antibody positive DM and CADM patients [20-22]. It was supposed that anti-MDA-5 antibody is associated with alveolar macrophage activation, thereby causing injury not only to the skin and lung, but also to the liver. 2) Furthermore, the $\mathrm{CD} 4^{+} / \mathrm{CD}^{+}$ratio in the BAL fluid was significantly higher in the positive group than in the negative group. No previous reports have compared the results of BAL analysis between anti-MDA- 5 antibody-positive and anti-MDA-5 antibody-negative CADM-ILD patients. Although it remains controversial whether the BAL lymphocyte subset is useful for clinical diagnosis of ILD, Suda et al. reported a higher $\mathrm{CD} 4^{+} / \mathrm{CD}^{+}$ratio in patients with acute/subacute CADM-ILD than chronic CADMILD [23]. Mukae et al. also showed a higher $\mathrm{CD}^{+} / \mathrm{CD}^{+}$ ratio in the BAL fluid of CADM patients than in those with classic DM [5]. In addition, Ito et al. found a higher $\mathrm{CD}^{+} / \mathrm{CD}^{+}$ratio in the BAL fluid of DM patients with RP-ILD than DM patients with chronic ILD [24]. These results provide further confirmation of our data.

As well as laboratory data, radiological findings were quite different between the two groups. In the present study, the most common HRCT pattern in the positive group was lower subpleural GGO followed by subpleural irregular linear opacity. Although no previous reports have clarified HRCT findings of anti-MDA-5 antibody-positive CADM-ILD, Tanizawa et al. reported that the most common HRCT pattern in anti-MDA-5 antibody-positive DM-ILD is lower GGO/consolidation (50\%) followed by random GGO (33 \%) [22]. Irregular linear opacities were also reported to be typical in CADM-ILD [13, 23, 25]. Intriguingly, the prevalence of GGO was significantly higher in 


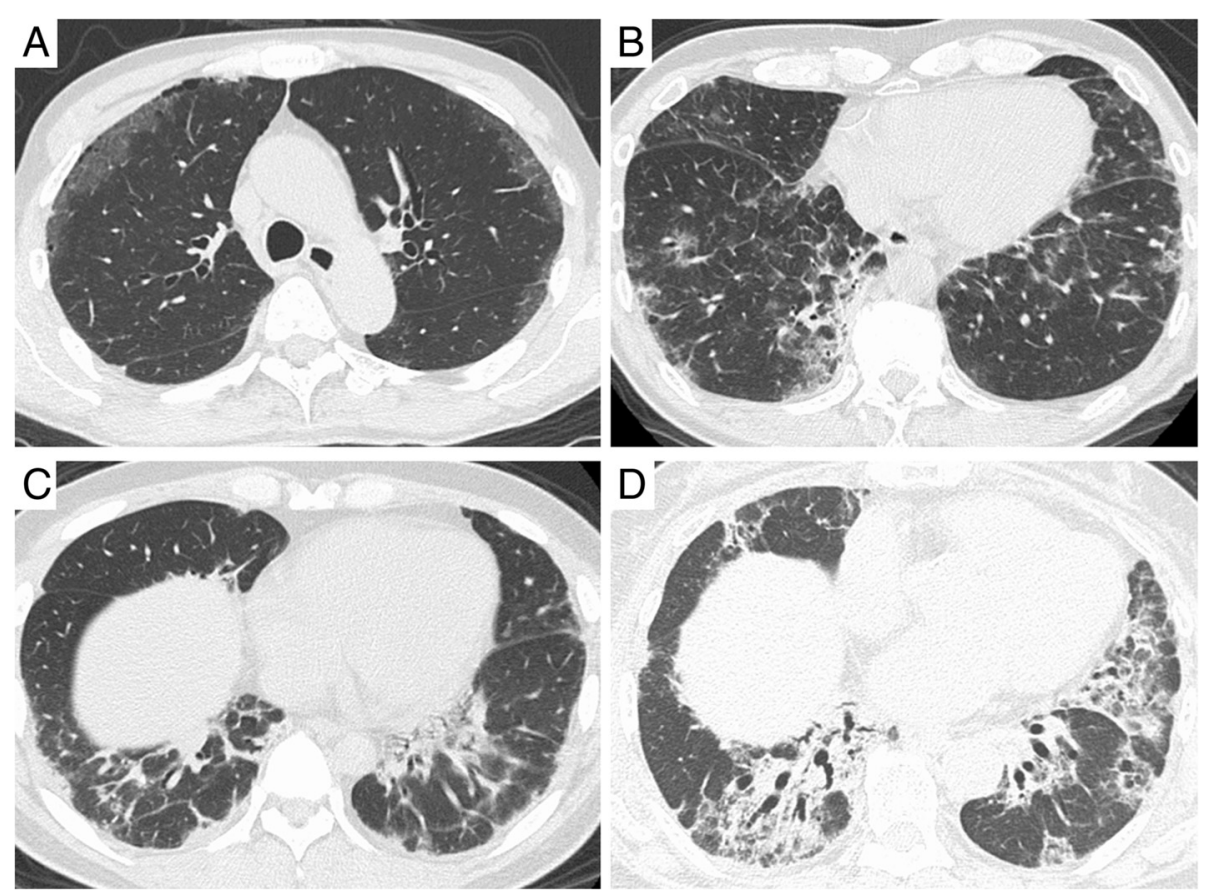

Fig. 2 High-resolution computed tomography findings. Representative photographs of HRCT scans are presented. $\mathbf{a}$ and $\mathbf{b}$ initial HRCT scans of fatal cases positive for anti-MDA-5 antibody showing subpleural GGO. (C) HRCT scans of an anti-MDA-5 antibody-positive patient who survived, showing subpleural irregular linear opacity. (D) HRCT scans of an anti-MDA-5 antibody-negative patient showing peribronchovascular consolidation. Abbreviations: GGO, ground-glass opacity; HRCT, high-resolution computed tomography; MDA-5, anti-melanoma differentiation-associated gene 5

non-survivors among anti-MDA-5 antibody-positive cases in the present study. Moreover, in one anti-MDA-5 antibody-positive case with subpleural GGO (as shown in Fig. 2a), autopsy revealed diffuse alveolar septal thickening due to organizing fibrosis, airspace organization, and hyaline membranes, suggesting a diffuse alveolar damage
(DAD) pattern. Although no reports have evaluated the histopathological findings of treatment-naïve CADM-ILD with anti-MDA-5 antibody, the pathological findings of autopsied lung in CADM-ILD with anti-MDA-5 antibody mostly revealed a DAD pattern [26-28]. Therefore, GGO in HRCT of anti-MDA-5 antibody-positive CADM-ILD

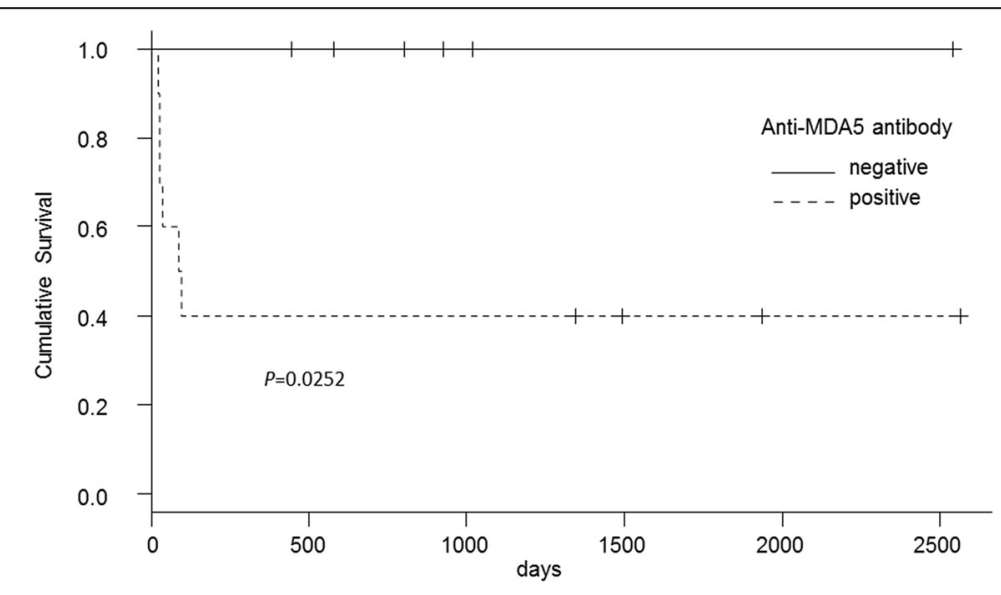

Number at risk

$\begin{array}{lcccccc}\text { negative } & 6 & 5 & 2 & 1 & 1 & 1 \\ \text { positive } & 10 & 4 & 4 & 2 & 1 & 1\end{array}$

Fig. 3 Comparison of survival curves with and without anti-MDA-5 antibody. Cumulative survival probabilities were estimated using the Kaplan-Meier method. The log-rank test was used to compare survival among patient groups. A p value of <0.05 was considered statistically significant. Abbreviation: MDA-5, anti-melanoma differentiation-associated gene 5 
Table 4 Comparisons of characteristics and examination findings between anti-MDA-5-positive survivors and non-survivors

\begin{tabular}{|c|c|c|c|}
\hline & $\begin{array}{l}\text { Survivors } \\
(n=4)\end{array}$ & $\begin{array}{l}\text { Non-survivors } \\
(n=6)\end{array}$ & $\begin{array}{l}p \\
\text { value }\end{array}$ \\
\hline Gender (male/female) & $2 / 2$ & $4 / 2$ & 1.00 \\
\hline Age & $58.5(47.8-64.3)$ & $63.0(59.3-64.5)$ & 0.519 \\
\hline \multicolumn{4}{|l|}{ Time } \\
\hline from onset to first visit & $29.5(26.0-50.3)$ & $11.0(11.0-13.3)$ & 0.0666 \\
\hline from onset to treatment initiation & $68.5(31.5-107)$ & $16.0(12.8-23.0)$ & 0.0381 \\
\hline \multicolumn{4}{|l|}{ Symptoms and signs } \\
\hline Gottron's sign & $2(50 \%)$ & $5(83 \%)$ & 0.500 \\
\hline Heliotrope eruption & $2(50 \%)$ & $5(83 \%)$ & 0.500 \\
\hline $\mathrm{V} /$ shawl neck sign & $1(25 \%)$ & $4(67 \%)$ & 0.524 \\
\hline Mechanic's hands & 0 & $2(33 \%)$ & 0.467 \\
\hline Palmar erythema & 0 & $2(33 \%)$ & 0.467 \\
\hline Myalgia & $2(50 \%)$ & $1(17 \%)$ & 0.500 \\
\hline Cough & $4(100 \%)$ & $1(17 \%)$ & 0.0480 \\
\hline Dyspnea on exertion & $3(75 \%)$ & $2(33 \%)$ & 0.524 \\
\hline Fever & $3(75 \%)$ & $6(100 \%)$ & 0.200 \\
\hline \multicolumn{4}{|l|}{ Laboratory data } \\
\hline Aspartate aminotransferase & $55.5(36.8-76.8)$ & $55.5(41.0-110)$ & 0.762 \\
\hline Y-glutamyl transpeptidase & $53.5(43.5-57.5)$ & $28.0(23.0-110)$ & 0.914 \\
\hline Krebs von den Lungen-6 & 1135 (930-1190) & $524(470-626)$ & 0.114 \\
\hline Surfactant protein D & $45.3(23.7-75.8)$ & $32.5(24.2-40.9)$ & 0.669 \\
\hline \multicolumn{4}{|l|}{ Bronchoalveolar lavage } \\
\hline $\mathrm{CD} 4+/ \mathrm{CD} 8+$ ratio & $3.52(2.12-4.04)$ & $1.47(1.20-2.19)$ & 0.857 \\
\hline \multicolumn{4}{|l|}{ HRCT findings } \\
\hline Consolidation & $1(25 \%)$ & 0 & 0.400 \\
\hline Ground glass opacity & 0 & $5(83 \%)$ & 0.0480 \\
\hline Reticulation & $1(25 \%)$ & 0 & 1.00 \\
\hline Irregular linear opacity & $2(50 \%)$ & $1(17 \%)$ & 0.500 \\
\hline
\end{tabular}

Categorical data are presented as numbers (percentages) and were analyzed using Fisher's exact test. Continuous data are presented as medians (interquartile ranges) and were analyzed using the Mann-Whitney $U$ test. A $p$ value of $<0.05$ was considered statistically significant

Abbreviations: HRCT high-resolution computed tomography, MDA-5, anti-melanoma differentiation-associated gene 5

may reflect the histopathology of DAD. On the contrary, peribronchovascular consolidation, which is suggestive of nonspecific interstitial pneumonia or organizing pneumonia, was most frequently observed in the negative group. Such CT patterns are generally observed in ILD with classic DM; in fact, anti-ARS antibody was detected in $50 \%$ of the negative cases.

These theories on the correlation between HRCT findings and pathological findings are supported by the differences in treatment response and prognosis between the two groups. The anti-MDA-5 antibody-positive cases had significantly lower survival rates than anti-MDA-5 antibody-negative cases; all six fatal cases were positive for anti-MDA-5 antibody and died from refractory ILD despite intensive initial treatment, whereas favorable treatment response and prognosis were observed in the negative group.

As described above, there are clear differences in the clinical features and prognosis between anti-MDA-5 antibody-positive and anti-MDA-5 antibody-negative CADM-ILD; thus, it would be appropriate to separate CADM-ILD by the presence or absence of anti-MDA-5 antibody. However, only a few medical facilities can measure anti-MDA-5 antibody levels, and it takes time to obtain test results; thus, the anti-MDA-5 antibody is not very helpful for deciding on a treatment policy and forecasting prognosis. Low levels of serum KL-6 and SP-D, high levels of serum AST, $\gamma-\mathrm{GTP}$, and $\mathrm{CD} 4^{+} / \mathrm{CD}^{+}$ ratio in BAL fluid, and the predominance of subpleural GGO or irregular linear opacity in HRCT may provide 
clues for discriminating anti-MDA-5 antibody-positive CADM-ILD with poor prognosis. On the other hand, the clinical features of anti-MDA-5 antibody-negative CADM-ILD appear rather similar to those of classical DM-ILD, and, thus, should probably not be considered as a distinct clinical entity from classic DM; continuous monitoring of muscle and other clinical symptoms is required.

A limitation of the present study is the retrospective single-center study design. The number of included patients was small, and the distribution of patients may have been skewed. Another important limitation to this study is the risk of multiple comparison testing. Because of the high number of statistical tests in spite of small number of the patients, some of these will yield a $p$-value of $<0.05$ by chance alone. As for ILD associated with CADM, there are regional and racial differences in the prevalence of ILD and the ratio of RP-ILD to the total population of CADM-ILD [1-4]. Additionally, the prevalence of anti-MDA-5 antibody is reportedly higher in Eastern Asia than in Europe or the US, although no previous studies have made direct comparisons [20, 21, 24, 29-31].

\section{Conclusions}

Anti-MDA-5 antibody-positive and anti-MDA-5 antibodynegative CADM-ILD have clearly different clinicoradiological features and prognosis, and, thus, it would be appropriate to separate CADM-ILD by the presence or absence of anti-MDA- 5 antibody. Further investigation with more cases is required to identify factors associated with poor prognosis among anti-MDA-5 antibody-positive CADM-ILD cases.

\section{Abbreviations \\ ILD: Interstitial lung disease; CADM: Clinically amyopathic dermatomyositis; MDA-5: Melanoma differentiation-associated gene 5; RP-ILD: Rapidly progressive ILD; KL-6: Krebs von den Lungen-6; SP-D: Surfactant protein D; AST: Aspartate aminotransferase; $\gamma$-GTP: $\gamma$-glutamyl transpeptidase; BAL: Bronchoalveolar lavage; GGO: Ground-glass opacity; HE: Hematoxylin and eosin; HRCT: High-resolution computed tomography.}

\section{Competing interests}

The authors declare that they have no competing interests.

\section{Authors' contributions}

Ikeda S, Arita M, and Morita M were involved in the acquisition of the data; Ikeda S, Arita M, Morita M, Ikeo S, Ito A, Tokioka F, Noyama M, and Misaki K were involved in the analysis and interpretation of the clinical data; Notohara K were involved in the analysis and interpretation of the pathological findings; lkeda S and Arita M were involved in the drafting of the manuscript; Ishida T was involved in the study supervision. All authors read and approved the final manuscript.

\section{Acknowledgements}

We would like to thank Motomu Hashimoto (Department of the Control for Rheumatic Diseases, Graduate School of Medicine, Kyoto University, Kyoto, Japan) for the detection of anti-MDA-5 antibody. We also thank Akimasa Sekine (Department of Respiratory Medicine, Kanagawa Cardiovascular and Respiratory Center, Yokohama, Japan) for editing the manuscript. This research received no specific grant from any funding agency in the public, commercial, or not-for-profit sectors.

\section{Author details}

'Department of Respiratory Medicine, Kurashiki Central Hospital, Miwa 1-1-1, Kurashiki-city, Okayama 710-8602, Japan. ${ }^{2}$ Department of Rheumatology, Kurashiki Central Hospital, Okayama, Japan. ${ }^{3}$ Department of Pathology,

Kurashiki Central Hospital, Okayama, Japan.

Received: 14 September 2015 Accepted: 30 November 2015

Published online: 09 December 2015

\section{References}

1. Sontheimer RD, Miyagawa S. Potentially fatal interstitial lung disease can occur in clinically amyopathic dermatomyositis. J Am Acad Dermatol. 2003; 48:797-8.

2. High WA, Cohen JB, Murphy BA, Costner MI. Fatal interstitial pulmonary fibrosis in anti-Jo-1-negative amyopathic dermatomyositis. J Am Acad Dermatol. 2003;49:295-8.

3. Ye $S$, Chen XX, Lu XY, Wu MF, Deng Y, Huang WQ, et al. Adult clinically amyopathic dermatomyositis with rapid progressive interstitial lung disease: a retrospective cohort study. Clin Rheumatol. 2007;26:1647-54.

4. Sun Y, Liu Y, Yan B, Shi G. Interstitial lung disease in clinically amyopathic dermatomyositis (CADM) patients: a retrospective study of 41 Chinese Han patients. Rheumatol Int. 2013;33:1295-302

5. Mukae H, Ishimoto H, Sakamoto N, Hara S, Kakugawa T, Nakayama S, et al. Clinical differences between interstitial lung disease associated with clinically amyopathic dermatomyositis and classic dermatomyositis. Chest. 2009;136:1341-7.

6. Nawata Y, Kurasawa K, Takabayashi K, Miike S, Watanabe N, Hiraguri M, et al. Corticosteroid resistant interstitial pneumonitis in dermatomyositis/ polymyositis: prediction and treatment with cyclosporine. J Rheumatol. 1999;26:1527-33.

7. Yamasaki Y, Yamada H, Yamasaki M, Ohkubo M, Azuma K, Matsuoka S, et al. Intravenous cyclophosphamide therapy for progressive interstitial pneumonia in patients with polymyositis/dermatomyositis. Rheumatology (Oxford). 2007:46:124-30.

8. Sato S, Hoshino K, Satoh T, Fujita T, Kawakami Y, Fujita T, et al. RNA helicase encoded by melanoma differentiation-associated gene 5 is a major autoantigen in patients with clinically amyopathic dermatomyositis: Association with rapidly progressive interstitial lung disease. Arthritis Rheum. 2009;60:2193.

9. Nakashima R, Imura Y, Kobayashi S, Yukawa N, Yoshifuji H, Nojima T, et al. The RIG-l-like receptor IFIH1/MDA5 is a dermatomyositis-specific autoantigen identified by the anti-CADM-140 antibody. Rheumatology (Oxford). 2010;49:433.

10. Chen Z, Cao M, Plana MN, Liang J, Cai H, Kuwana M, et al. Utility of anti-melanoma differentiation-associated gene 5 antibody measurement in identifying patients with dermatomyositis and a high risk for developing rapidly progressive interstitial lung disease: a review of the literature and a meta-analysis. Arthritis. Care. Res (Hoboken). 2013;65:1316-24.

11. Sontheimer RD. Would a new name hasten the acceptance of amyopathic dermatomyositis (dermatomyositis siné myositis) as a distinctive subset within the idiopathic inflammatory dermatomyopathies spectrum of clinical illness? J Am Acad Dermatol. 2002:46:626-36.

12. Gerami P, Schope JM, McDonald L, Walling HW, Sontheimer RD. A systematic review of adult-onset clinically amyopathic dermatomyositis (dermatomyositis siné myositis): a missing link within the spectrum of the idiopathic inflammatory myopathies. J Am Acad Dermatol. 2006;54:597-613.

13. Cottin V, Thivolet-Bejui F, Reynaud-Gaubert M, Cadranel J, Delaval P, Ternamian PJ, et al. Groupe d'Etudes et de Recherche sur les Maladies "Orphelines" Pulmonaires. Interstitial lung disease in amyopathic dermatomyositis, dermatomyositis and polymyositis. Eur Respir J. 2003;22:245-50.

14. Kubo M, Ihn H, Yamane K, Kikuchi K, Yazawa N, Soma Y, et al. Serum KL-6 in adult patients with polymyositis and dermatomyositis. Rheumatology (Oxford). 2000;39:632-6.

15. Fathi M, Barbasso Helmers S, Lundberg IE. KL-6: a serological biomarker for interstitial lung disease in patients with polymyositis and dermatomyositis. J Intern Med. 2012;271:589-97.

16. Ihn H, Asano Y, Kubo M, Yamane K, Jinnin M, Yazawa N, et al. Clinical significance of serum surfactant protein D (SP-D) in patients with polymyositis/ dermatomyositis: correlation with interstitial lung disease. Rheumatology (Oxford). 2002;41:1268-72. 
17. Otsuka M, Takahashi H, Fujisima T, Nishiyama K, Kon H, Outi H, et al. New serum markers to monitor treatment of acute exacerbation of interstitial lung disease. Nihon Kokyuki Gakkai Zasshi. 2001;39:298-302.

18. Sakamoto $K$, Taniguchi $H$, Kondoh $Y$, Johkoh T, Sumikawa $H$, Kimura T, et al. Serum KL-6 in fibrotic NSIP: Correlations with physiologic and radiologic parameters. Respir Med. 2010;104:127-33.

19. Takahashi H, Fujishima T, Koba H, Murakami S, Kurokawa K, Shibuya Y, et al. Serum surfactant proteins $A$ and $D$ as prognostic factors in idiopathic pulmonary fibrosis and their relationship to disease extent. Am J Respir Crit Care Med. 2000;162:1109-14.

20. Koga T, Fujikawa K, Horai Y, Okada A, Kawashiri SY, Iwamoto N, et al. The diagnostic utility of anti-melanoma differentiation-associated gene 5 antibody testing for predicting the prognosis of Japanese patients with DM. Rheumatology (Oxford). 2012;51:1278-84.

21. Gono T, Kawaguchi Y, Satoh T, Kuwana M, Katsumata Y, Takagi K, et al. Clinical manifestation and prognostic factor in anti-melanoma differentiation-associated gene 5 antibody-associated interstitial lung disease as a complication of dermatomyositis. Rheumatology (Oxford). 2010;49:1713-9.

22. Tanizawa K, Handa T, Nakashima R, Kubo T, Hosono Y, Watanabe K, et al. HRCT features of interstitial lung disease in dermatomyositis with anti-CADM-140 antibody. Respir Med. 2011;105:1380-7.

23. Suda T, Fujisawa $T$, Enomoto $N$, Nakamura $Y$, Inui $N$, Naito $T$, et al. Interstitial lung diseases associated with amyopathic dermatomyositis. Eur Respir J. 2006:28:1005-12

24. Ito M, Kaise S, Suzuki S, Kazuta Y, Sato Y, Miyata M, et al. Clinico-laboratory characteristics of patients with dermatomyositis accompanied by rapidly progressive interstitial lung disease. Clin Rheumatol. 1999;18:462-7.

25. Lee CS, Chen TL, Tzen CY, Lin FJ, Peng MJ, Wu CL, et al. Idiopathic inflammatory myopathy with diffuse alveolar damage. Clin Rheumatol. 2002;21:391-6.

26. Sakurai N, Nagai K, Tsutsumi H, Ichimiya S. Anti-CADM-140 antibody juvenile dermatomyositis with rapidly progressive interstitial lung disease and cardiac involvement. J Rheumatol. 2011;38:963-4.

27. Morita Y, Kuwagata S, Kato N, Tsujimura Y, Mizutani H, Suehiro M, et al. 18F-FDG PET/CT useful for the early detection of rapidly progressive fatal interstitial lung disease in dermatomyositis. Intern Med. 2012;51:1613-8.

28. Miyake M, Sakai A, Nishijima C, Kita T, Nitta E, Kawashima A, et al. Detection of anti-CADM-140/MDA5 antibodies in a patient with classic dermatomyositis developing rapidly progressive interstitial lung disease. J Dermatol. 2014:41:664-5.

29. Miyazaki E, Ando M, Muramatsu T, Fukami T, Matsuno O, Nureki S, et al. Early assessment of rapidly progressive interstitial pneumonia associated with amyopathic dermatomyositis. Clin Rheumatol. 2007;26:436-9.

30. Chow SK, Yeap SS. Amyopathic dermatomyositis and pulmonary fibrosis. Clin Rheumatol. 2000:19:484-5.

31. Hoshino K, Muro Y, Sugiura K, Tomita Y, Nakashima R, Mimori T. Anti-MDA5 and anti-TIF1-gamma antibodies have clinical significance for patients with dermatomyositis. Rheumatology (Oxford). 2010;49:1726-33.

\section{Submit your next manuscript to BioMed Central and we will help you at every step:}

- We accept pre-submission inquiries

- Our selector tool helps you to find the most relevant journal

- We provide round the clock customer support

- Convenient online submission

- Thorough peer review

- Inclusion in PubMed and all major indexing services

- Maximum visibility for your research 